\title{
Postmastectomy Radiotherapy Improves Survival Benefits in De Novo Stage IV Breast Cancer: A Propensity-Score Matched Analysis
}

Ning Liang

Shandong Qianfoshan Hospital

\section{Xinyi Huang}

Shandong University

Tiantian Tian

Shandong Qianfoshan Hospital

Pingping Hu ( $\nabla$ hupingping0915@126.com )

Shandong Qianfoshan Hospital https://orcid.org/0000-0001-9925-0939

\section{Research Article}

Keywords: Breast cancer, Postmastectomy radiotherapy, Stage IV, Metastasis, Survival

Posted Date: May 5th, 2021

DOl: https://doi.org/10.21203/rs.3.rs-463247/v1

License: (9) This work is licensed under a Creative Commons Attribution 4.0 International License. Read Full License 


\section{Abstract}

Purpose: The role of postmastectomy radiotherapy (PMRT) in patients with de novo stage IV breast cancer is unclear. This study aimed to evaluate the value of PMRT for metastatic breast cancer who underwent a modified radical mastectomy.

Methods: Data on de novo stage IV breast cancer patients who received modified radical mastectomy between 2010 and 2015 were retrieved from the Surveillance, Epidemiology, and End Results (SEER) database. Propensity score matching (PSM) analysis was conducted to balance baseline clinical characteristics. The prognostic roles of PMRT on cancer-specific survival (CSS) and overall survival (OS) were analyzed using the Kaplan-Meier method and Cox proportional hazard models.

Results: A total of 1944 patients were enrolled before PMS. After PMS, 1458 patients were included. PMRT improved prognosis in both CSS and OS. Multivariate Cox analysis showed that PMRT was independently prognostic for CSS (HR $0.739,95 \% \mathrm{Cl}$. 0.619-0.884, $\mathrm{P}=0.001)$ and OS (HR $0.744,95 \% \mathrm{Cl}$ $0.628-0.8810, P=0.001)$. Further subgroup analyses found that survival superiority was observed in T3-4 or $\mathrm{N}+$ subgroup (both $\mathrm{P}<0.001$ for CSS and OS), and Her2-/HR+ breast subtype (HR $0.703,95 \% \mathrm{Cl} 0.558$ 0.888 for CSS, and HR $0.712,95 \% \mathrm{Cl} 0.573-0.885$ for OS), especially in patients with bone metastasis but without brain metastasis.

Conclusion: PMRT improved survival in de novo stage IV breast cancer patients in selected T3-4 or N+ subgroup and Her2-/HR+ breast subtype. However, these findings need to be validated by further study before being incorporated into clinical practice.

\section{Introduction}

Less than $10 \%$ of newly diagnosed breast cancer (BC) presented with metastasis [1]. This group of patients is centered mainly around systemic therapy, including chemotherapy, hormonal therapy, or targeted therapy. Local therapy (surgery and/or radiation therapy) was performed with palliative intent [2]. Locoregional treatment was usually performed in those with significant symptoms from the primary site, such as bleeding, infection, pain, etc. Some studies reported removal of the primary tumor might improve survival, while other studies showed no apparent survival benefit. This topic has been discussed earlier by Barbie TU [3]. Therefore, evidence of survival benefits with surgery in de novo stage IV BC in the literature has been conflicting [4].

Although metastatic $\mathrm{BC}$ cannot be cured, many patients in this stage can survive longer. Existing evidence from retrospective and prospective studies has not drawn definitive conclusions on the survival benefits of breast surgery in metastatic BC. Until now, breast surgery has been individually performed after the doctors consider possible risks, benefits, and treatment costs with patients [4]. The intervention to primary BC mainly consists of conservative (lumpectomy) or radical surgery (mastectomy), and radiotherapy may be a component of locoregional treatment. The benefits of RT after breast-conserving surgery have been proven in early BC patients. According to the NCCN guideline, PRMT is considered or 
strongly considered for T3-4N0 or positive axillary nodes breast cancer patients. In the de novo stage IV $\mathrm{BC}$, who underwent a modified radical mastectomy, PMRT was given to patients according to each institutional policy and the physician's discretion. Although these patients comprised the minority, radiation oncologists sometimes faced the challenge of whether PMRT is delivered or not.

Survival benefit of PMRT was also observed in locally advanced BC patients who achieved pathologic complete response (pCR) after neoadjuvant chemotherapy [5]. RT performed alone or after breast surgery was demonstrated more favorable outcomes in Stage IV BC [7, 8]. External beam radiotherapy to the chest wall with or without the regional node was conventionally performed currently due to the lack of sophisticated research evaluating the role of PMRT in metastatic BC. It is unclear whether PMRT in this population will translate into survival benefit or lead to just an overtreatment.

Given this uncertainty, we formed this study based on the US Surveillance, Epidemiology, and End Results-(SEER) database, mainly aim to explore the question of whether de novo stage IV BC benefit from PMRT after a modified radical mastectomy. To decline the selection bias and produce more confident results on the effect of PMRT, additional propensity score matching (PSM) was performed.

\section{Methods}

Patients and database

Patients with de novo stage IV BC between 2010 and 2015 were retrieved from the SEER database. Patients who underwent surgical excision of primary breast tumor with modified radical mastectomy were included. Patients with missing information on $\mathrm{T}$ or $\mathrm{N}$ stage, unknown status of breast subtype, a history of a previous tumor, not RT after surgery, and unknown radiation-surgery sequence were excluded from the analysis.

Clinical characteristics including age, sex, $\mathrm{T}$ stage, $\mathrm{N}$ stage, breast subtype, and metastasis site were collected. Treatment modalities such as surgery, radiotherapy, and chemotherapy were obtained. The lack of information about other systemic therapies, including endocrine therapy and targeted therapy, has prevented a detailed analysis of these variables.

PMRT effect following mastectomy was analyzed. Cancer-specific survival (CSS) was calculated from the death of breast cancer, and for overall survival (OS), any death is an event. BC patients have been previously de-identified by SEER. Therefore, no institutional review board approval was needed for the study.

\section{Statistical analysis}

The PSM analysis was performed between the PMRT group and the non-PMRT group with a logistic regression that included age, $\mathrm{T}$ stage, $\mathrm{N}$ stage, breast subtype, and chemotherapy. We used a 1:1 "nearest" matching algorithm with a caliper distance of 0.02 . 
The $\chi 2$ test or Fisher's exact test was used to compare categorical variables in PMRT and non-PMRT groups. CSS and OS were analyzed using the Kaplan-Meier method with log-rank tests. Univariate and multivariate Cox proportional hazard models were used to estimate the survival prognosticators in de novo stage IV BC, and multivariate Cox analysis was performed with a stepwise forward method.

Statistical analyses were conducted using R (V.3.5.0, the R Foundation for Statistical Computing, Vienna, Austria) or SPSS 20.0 (SPSS Inc., Chicago, IL, USA) software. The forest plot was performed with Stata Statistical Software (Version 12.0). A P value $<0.05$ was judged to be statistically significant.

\section{Results}

Cohort

Between 2010 and 2015, the study included 1944 patients. Details for patient enrolment were summarized in a flow chart (Fig. 1). Among these patients, 844 (43.4\%) patients underwent PMRT, and 1100 (56.6\%) had a mastectomy without PMRT. The median patient age was 58 (range 21-98) years. 1916 patients were female, and 28 patients were male. The information on the metastasis site was not available for all patients or all sites. Only metastases at the lung, liver, bone, and brain were reported, while other distant metastases in known site(s) such as the adrenal, pleura, malignant pleural effusion, and peritoneum were not reported. Information on lung metastasis, liver metastasis, bone metastasis, and brain metastasis was available for 1888, 1903, 1916, and 1896 patients, respectively.

The clinical characteristics differed between the two groups. Patients received PMRT were more likely related to young age (48.8\% in age $\leq 65$ and $29.7 \%$ in age $>65, P<0.001)$, advanced $T$ stage $(45.5 \%$ in T3-4 group and $40.2 \%$ in T0-2 group, $\mathrm{P}=0.022$ ), lymph node metastasis ( $44.1 \%$ in $\mathrm{N}$ positive group and $30.3 \%$ in $\mathrm{N}$ negative group, $\mathrm{P}=0.009)$, and receiving chemotherapy ( $50.0 \%$ in the chemotherapy group and $25.3 \%$ in no/unknown-chemotherapy group, $\mathrm{P}<0.001$ ). The PSM analysis was performed to balance the baseline characteristics with the following covariates: age, T stage, $\mathrm{N}$ stage, breast subtype, and chemotherapy. A total of 729 patients in each group was included after PSM. No significant differences were found in clinical characteristics between the PMRT and non-PMRT group. Detailed clinical characteristics were listed in Table 1. Further analyses were performed in the matched cohorts. 
Table 1

Baseline patient characteristics.

Before PSM ( $N=1944)$

\section{Factors}

Age

$\leq 65$

$>65$

Female

Sex

T stage

Negative

T3-4 or $\mathrm{N}+\quad$ Yes

Positive

No

Chemotherapy Yes

No/Unknown

Breast

subtype

$\begin{array}{ll}131 & 387(74.7)\end{array}$

Triple

negative

$186(56.5)$

143
$(43.5)$
PMRT Non-PMRT P

No. (\%)

No.

(\%)

$\begin{array}{llll}681 & 715(51.2) & < & 566 \\ (48.8) & & 0.001 & (50.2)\end{array}$

$163 \quad 385(70.3)$

(29.7)

829
$(43.3)$

15

(53.6)

$13(46.4)$

304
$(40.2)$

540

(45.5)

814
$(44.1)$

30

(30.3)

833

(43.8)

$11 \quad 33(75.0)$

(25.0)

713

(50.0)

$453(59.8)$

$647(54.5)$

$1031(55.9)$

$69(69.7)$

1067 (56.2)

0.013

(50.0)

461
$(50.1)$

12
$(63.2)$

163
$(49.4)$

717

(49.8)

268

(49.8)

(49.9)

(53.7)

(52.6) $0.001 \quad(50.0)$

$562(49.8) \quad 0.851$

$167(50.6)$

$722(50.2) \quad 0.248$

$7(36.8)$

$270(50.2) \quad 0.914$

459 (49.9)

$704(50.1) \quad 0.678$

$29 \quad 25(46.3)$

$719 \quad 720(50.0) \quad 1.000$

$10 \quad 9(47.4)$

$598 \quad 598(50.0) \quad 1.000$

131

(50.0)

$131(50.0)$

0.956

117

(50.6)

$114(49.4)$

0.997

Her2+/HR+

147

(42.2)

$201(57.8)$

130

(49.8)

$131(50.2)$

Her2+/HR-

90

(42.9)

$120(57.1)$

79
$(50.0)$

$79(50.0)$

Abbreviations: HR, hormone receptor; PSM, propensity score matching. 


\begin{tabular}{|cllll|}
\hline \multicolumn{4}{|c|}{ Before PSM (N = 1944) } & \multicolumn{2}{c|}{ After PSM (N= 1458) } \\
\hline Her2-/HR+ & $\begin{array}{llll}464 \\
(43.9)\end{array}$ & $593(56.1)$ & 403 & $405(50.1)$ \\
& & & $(49.9)$ & \\
\hline
\end{tabular}

\section{Survival analysis}

Using Kaplan-Meier survival curves, significant differences of CSS and OS were demonstrated by log-rank test $(P=0.001$ for CSS, and $P<0.001$ for OS). The median CSS was 43 months for the non-PMRT group and 54 months for the PMRT group. The median OS was 39 months and 49 months for the non-PMRT group and PMRT group, respectively (Fig. 2A-B).

Survival prognosticators, including sex, age, breast subtype (Triple Negative, Her2+/ Hormone receptor $(\mathrm{HR})+, \mathrm{Her} 2+/ \mathrm{HR}-$, and Her2-/HR+), $\mathrm{T}$ and $\mathrm{N}$ stage, chemotherapy, and metastatic sites were included in the Cox proportional hazard models analysis (Table 2-3). Multivariate analysis demonstrated that treatment with PMRT was an independent positive predictor for CSS (HR 0.739, 95\% Cl. 0.619-0.884, P = $0.001)$, together with non-triple negative breast subtype ( $P \otimes 0.001)$, and receiving chemotherapy $(P=$ 0.031). The patients with brain metastasis had the worst CSS (HR 2.811,95\% Cl 1.880-4.203), followed by lung metastasis (HR 1.595, 95\% Cl 1.304-1.952), liver metastasis (HR 1.455,95\% Cl 1.170-1.809), and bone metastasis (HR 1.262,95\% Cl 1.043-1.527) (Table 2). Similar results were observed for OS, with PMRT was an independent favorable prognostic factor $(\mathrm{HR} 0.744,95 \% \mathrm{Cl} 0.628-0.881, \mathrm{P}=0.001)$ (Table 3). 
Table 2

Univariable and multivariable Cox regression analyses for CSS in patients after PSM.

\begin{tabular}{|c|c|c|c|c|c|}
\hline & & Univariable & & Multivariable & \\
\hline Covariates & & $\mathrm{HR}(95 \% \mathrm{Cl})$ & $P$ & $\mathrm{HR}(97 \% \mathrm{Cl})$ & $P$ \\
\hline \multirow[t]{2}{*}{ Age } & $\leq 65$ & 1[Reference] & 0.106 & & * \\
\hline & $₫ 65$ & $\begin{array}{l}1.181(0.965- \\
1.446)\end{array}$ & & & \\
\hline \multirow[t]{2}{*}{ Sex } & Female & 1[Reference] & 0.545 & & * \\
\hline & Male & $0.780(0.349-1,745)$ & & & \\
\hline \multirow[t]{4}{*}{ Breast subtype } & $\begin{array}{l}\text { Triple } \\
\text { negative }\end{array}$ & 1.00 (Reference) & $\varangle 0.001$ & 1.00 (Reference) & $\nabla 0.001$ \\
\hline & $\mathrm{Her} 2+/ \mathrm{HR}^{\dagger}+$ & $0.219(0.163-0.295)$ & & $\begin{array}{l}0.203(0.149- \\
0.276)\end{array}$ & \\
\hline & Her2+/HR ${ }^{\dagger}-$ & $\begin{array}{l}0.258(0.183- \\
0.364)\end{array}$ & & $\begin{array}{l}0.227(0.157- \\
0.327)\end{array}$ & \\
\hline & Her2-/ $/ \mathrm{HR}^{\dagger}+$ & $\begin{array}{l}0.320(0.261- \\
0.392)\end{array}$ & & $\begin{array}{l}0.312(0.249- \\
0.392)\end{array}$ & \\
\hline \multirow[t]{2}{*}{ T3-4 or $\mathrm{N}$} & No & 1 & 0.903 & & * \\
\hline & Yes & $\begin{array}{l}0.903(0.467- \\
1.746)\end{array}$ & & & \\
\hline \multirow[t]{2}{*}{ Chemotherapy } & No/Unknown & 1.00 (Reference) & 0.031 & 1.00 (Reference) & 0.005 \\
\hline & Yes & $\begin{array}{l}0.794(0.643- \\
0.980)\end{array}$ & & $\begin{array}{l}0.714(0.566- \\
0.901)\end{array}$ & \\
\hline \multirow{2}{*}{$\begin{array}{l}\text { Bone } \\
\text { metastasis }\end{array}$} & No & 1[Reference] & 0.535 & $1[$ Reference] & 0.017 \\
\hline & Yes & $0.947(0.797-1.125$ & & $\begin{array}{l}1.262(1.043- \\
1.527)\end{array}$ & \\
\hline \multirow{2}{*}{$\begin{array}{l}\text { Brain } \\
\text { metastasis }\end{array}$} & No & 1[Reference] & $\varangle 0.001$ & 1[Reference] & $\triangle 0.001$ \\
\hline & Yes & $\begin{array}{l}2.593(1.759- \\
3.821)\end{array}$ & & $\begin{array}{l}2.811(1.880- \\
4.203)\end{array}$ & \\
\hline Liver metastasis & No & 1[Reference] & 0.001 & 1[Reference] & 0.001 \\
\hline
\end{tabular}

Abbreviations: PSM, propensity score matching; $\mathrm{HR}$, hazard ratio; $\mathrm{Cl}$, confidence interval; $\mathrm{HR}^{\dagger}$, hormone receptor; PMRT, postmastectomy radiotherapy; *, Not in the final step of multivariate analysis. 


\begin{tabular}{|c|c|c|c|c|c|}
\hline & & \multicolumn{2}{|l|}{ Univariable } & \multicolumn{2}{|l|}{ Multivariable } \\
\hline & Yes & $\begin{array}{l}1.423(1.159- \\
1.748)\end{array}$ & & $\begin{array}{l}1.455(1.170- \\
1.809)\end{array}$ & \\
\hline \multirow{2}{*}{$\begin{array}{l}\text { Lung } \\
\text { metastasis }\end{array}$} & No & 1[Reference] & $\otimes 0.001$ & 1[Reference] & $\nabla 0.001$ \\
\hline & Yes & $\begin{array}{l}1.757(1.451- \\
2.129)\end{array}$ & & $\begin{array}{l}1.595(1.304- \\
1.952)\end{array}$ & \\
\hline \multirow[t]{2}{*}{ PMRT } & No & 1[Reference] & 0.001 & 1[Reference] & 0.001 \\
\hline & Yes & $\begin{array}{l}0.745(0.629- \\
0.882)\end{array}$ & & $\begin{array}{l}0.739(0.619- \\
0.884)\end{array}$ & \\
\hline
\end{tabular}


Table 3

Univariable and multivariable Cox regression analyses for OS in patients after PSM.

\begin{tabular}{|c|c|c|c|c|c|}
\hline & & Univariable & & Multivariable & \\
\hline Covariates & & $\mathrm{HR}(95 \% \mathrm{Cl})$ & $P$ & $\mathrm{HR}(97 \% \mathrm{Cl})$ & $\mathrm{P}$ \\
\hline \multirow[t]{2}{*}{ Age } & $\leq 65$ & 1[Reference] & 0.002 & & * \\
\hline & $\$ 65$ & $\begin{array}{l}1.349(1.121- \\
1.624)\end{array}$ & & & \\
\hline \multirow[t]{2}{*}{ Sex } & Female & 1[Reference] & 0.862 & & * \\
\hline & Male & $\begin{array}{l}0.940(0.468- \\
1.889)\end{array}$ & & & \\
\hline \multirow[t]{4}{*}{ Breast subtype } & $\begin{array}{l}\text { Triple } \\
\text { negative }\end{array}$ & 1.00 (Reference) & $\nabla 0.001$ & 1.00 (Reference) & $\nabla 0.001$ \\
\hline & Her2 $+/ \mathrm{HR}^{\dagger}+$ & $\begin{array}{l}0.236(0.178- \\
0.313)\end{array}$ & & $\begin{array}{l}0.224(0.167- \\
0.301)\end{array}$ & \\
\hline & Her2+/HR ${ }^{\dagger}-$ & $\begin{array}{l}0.265(0.190- \\
0.370)\end{array}$ & & $\begin{array}{l}0.239(0.168- \\
0.340)\end{array}$ & \\
\hline & Her2-/ $/ \mathrm{HR}^{+}+$ & $\begin{array}{l}0.349(0.287- \\
0.424)\end{array}$ & & $\begin{array}{l}0.336(0.270- \\
0.418)\end{array}$ & \\
\hline \multirow[t]{2}{*}{ T3-4 or $\mathrm{N}$} & No & 1[Reference] & 0.740 & & * \\
\hline & Yes & $0.900(0.481-1.681)$ & & & \\
\hline \multirow[t]{2}{*}{ Chemotherapy } & No/Unknown & 1[Reference] & 0.001 & 1 [Reference] & $\bowtie 0.001$ \\
\hline & Yes & $\begin{array}{l}0.712(0.586- \\
0.864)\end{array}$ & & $\begin{array}{l}0.651(0.525- \\
0.808)\end{array}$ & \\
\hline \multirow{2}{*}{$\begin{array}{l}\text { Bone } \\
\text { metastasis }\end{array}$} & No & 1[Reference] & 0.576 & 1[Reference] & 0.044 \\
\hline & Yes & $0.954(0.810-1.124)$ & & $\begin{array}{l}1.205(1.005- \\
1.444)\end{array}$ & \\
\hline \multirow{2}{*}{$\begin{array}{l}\text { Brain } \\
\text { metastasis }\end{array}$} & No & 1[Reference] & $\otimes 0.001$ & 1 [Reference] & $\otimes 0.001$ \\
\hline & Yes & $\begin{array}{l}2.630(1.820- \\
3.800)\end{array}$ & & $\begin{array}{l}2.909 \text { (1.987- } \\
4.258)\end{array}$ & \\
\hline Liver metastasis & No & 1 [Reference] & 0.003 & 1[Reference] & 0.002 \\
\hline
\end{tabular}

Abbreviations: PSM, propensity score matching; $\mathrm{HR}$, hazard ratio; $\mathrm{Cl}$, confidence interval; $\mathrm{HR}^{\dagger}$, hormone receptor; PMRT, postmastectomy radiotherapy; ${ }^{*}$, Not in the final step of multivariate analysis. 


\begin{tabular}{|c|c|c|c|c|c|}
\hline & & Univariable & & Multivariable & \\
\hline & Yes & $\begin{array}{l}1.349(1.107- \\
1.645)\end{array}$ & & $\begin{array}{l}1.405(1.138- \\
1.734)\end{array}$ & \\
\hline \multirow{2}{*}{$\begin{array}{l}\text { Lung } \\
\text { metastasis }\end{array}$} & No & 1[Reference] & $\nabla 0.001$ & 1 [Reference] & $\nabla 0.001$ \\
\hline & Yes & $\begin{array}{l}1.667(1.386- \\
2.005)\end{array}$ & & $\begin{array}{l}1.507(1.241- \\
1.830)\end{array}$ & \\
\hline \multirow[t]{2}{*}{ PMRT } & No & 1[Reference] & 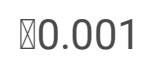 & 1[Reference] & 0.001 \\
\hline & Yes & $\begin{array}{l}0.749(0.638- \\
0.880)\end{array}$ & & $\begin{array}{l}0.744(0.628- \\
0.881)\end{array}$ & \\
\hline $\begin{array}{l}\text { Abbreviation } \\
\text { hormone rec } \\
\text { analysis. }\end{array}$ & prop & $\begin{array}{l}\text { matching; } \mathrm{HR} \text {, } \\
\text { tomy radiother }\end{array}$ & $\begin{array}{l}\text { atio; } \mathrm{Cl}, \\
\text { t in the }\end{array}$ & $\begin{array}{l}\text { nfidence interv } \\
\text { lal step of mult }\end{array}$ & \\
\hline
\end{tabular}

T3-4N0 or positive axillary nodes was a current clinical indication for PMRT in nonmetastatic BC.

Therefore, we performed the subgroup analysis due to the T and N stages. Subgroup analyses found that CSS and OS were statistically longer in the PMRT group than in the non-PMRT group, especially in T3-4 or $\mathrm{N}+$ subgroup (both $\mathrm{P}<0.001$ for CSS and OS) (Fig. 3A and B). However, in the T0-2 and N-group, the PMRT group showed a significantly poor survival $(P=0.028$ for CSS and $P=0.017$ for OS) (Fig. $3 \mathrm{C}$ and D).

Considering the different outcome of breast cancer subtypes, we then performed subgroup analyses in different subtypes. PMRT was associated with favorable CSS in Her2-/HR + breast subtype (HR 0.703, $95 \% \mathrm{Cl} 0.558-0.888, \mathrm{P}=0.003$ ), while no statistical difference was found in triple negative (HR $0.763,95 \%$ $\mathrm{Cl} 0.551-1.057, \mathrm{P}=0.104)$, Her2+/HR- subtype (HR 0.900, 95\% Cl 0.494-1.639, $\mathrm{P}=0.731)$ and Her2+/HR+ (HR $0.669,95 \% \mathrm{Cl} 0.408-1.097, \mathrm{P}=0.111)$. This trend remained consistently in OS that PMRT improved OS in Her2-/HR + breast subtype (HR $0.712,95 \% \mathrm{Cl} 0.573-0.885, \mathrm{P}=0.002)$, instead of in triple negative (HR $0.765,95 \% \mathrm{Cl} 0.555-1.053, \mathrm{P}=0.100)$ and Her2+/HR- subtype (HR 0.869, 95\% Cl 0.486-1.552, $\mathrm{P}=$ $0.635)$ and Her2+/HR+ (HR 0.685, 95\% Cl 0.431-1.091, $\mathrm{P}=0.111)$ (Fig. 4A).

Subgroup analyses according to the site of metastasis

Only the information of four common metastasis sites, including the brain, liver, lung, and bone, was available in some patients. To explore the impact of the specific metastatic site, further analyses were conducted in the T3-4 or $\mathrm{N}+$ with Her2-/HR + patients who were established with clinical benefit from PMRT. The information on the metastasis site was reported in 760 patients. When simply stratified by the metastasis site, CSS was statistically longer in the PMRT group than in the non-PMRT group in bone metastasis (HR 0.717, 95\% Cl 0.535-0. 0.960, P = 0.025, while no statistical difference was observed in OS between PMRT and non-PMRT group (HR 0.782, 95\% $\mathrm{Cl} 0.594-1.030, \mathrm{P}=0.08)$. No survival benefit was observed in brain metastasis (HR 2.53, 95\% Cl 0.315-20.32, P = 0.383 for CSS; HR 1.811, 95\% Cl 0.3888.451, $\mathrm{P}=0.450$ for OS), liver metastasis (HR $0.702,95 \% \mathrm{Cl} 0.400-1.232, \mathrm{P}=0.218$ for CSS; HR 0.702 , 
$95 \% \mathrm{Cl} 0.406-1.213, \mathrm{P}=0.205$ for OS) and lung metastasis ( $\mathrm{HR} 0.825,95 \% \mathrm{Cl} 0.481-1.415, \mathrm{P}=0.484$ for CSS; HR $0.794,95 \% \mathrm{Cl} 0.470-1.342, \mathrm{P}=0.389$ for OS) (Fig. 4B).

Given that brain metastasis significantly impacted the outcome based on the previously described results, we performed further analysis in the 743 patients without brain metastasis. We found that PMRT significantly improved CSS and OS in the bone metastasis without brain metastasis group (HR 0.678, $95 \% \mathrm{Cl} 0.504-0.911, \mathrm{P}=0.01$ for CSS; HR $0.73,95 \% \mathrm{Cl} 0.551-0.965, \mathrm{P}=0.027$ for OS). The median CSS and OS for the PMRT group were 56 and 52 months, and that for non-PMRT groups were 44 and 42 months ( $P=0.009$ for CSS and $P=0.025$ for OS, respectively). However, the survival benefits were not observed in the liver metastasis without brain metastasis (HR 0.648, 95\% Cl 0.361-1.161, P = 0.145 for CSS; HR $0.651,95 \% \mathrm{Cl} 0.369-1.149, \mathrm{P}=0.139$ for OS), and lung metastasis without brain metastasis groups (HR 0.688, 95\% Cl 0.390-1.217, P= 0.199 for CSS; HR 0.667, 95\% Cl 0.384-1.158, $P=0.150$ for OS) (Fig. 4C).

\section{Discussion}

Management of de novo stage IV BC remains a controversial issue for surgeons. Primary tumor resection was performed based on the following indications, such as severe tumor pain, uncontrollable bleeding, unmanageable wound care, and patient preference. It also brings a challenging task for radiation oncologists to proceed with RT in postoperative patients, although these patients are only in the minority. Currently, retrospective evidence on the role of PMRT for metastatic BC is lacking, and no randomized studies have yet evaluated this subject. As a result, indications for PMRT are inconclusive. No specific recommendations were given for PMRT in the particular stage IV BC group underwent a modified radical mastectomy. Should PMRT be given when a radiation oncologist encounters a metastatic BC patient who underwent a modified radical mastectomy? We performed this study to explore the clinical value of PRMT in stage IV BC patients. To minimize the bias related to treatment allocation, we used the PSM analysis to adjust the baseline clinical characteristics. This large retrospective study with long term follow-up has confirmed the survival benefit of PMRT in selected T3-4 or N + subgroup and Her2-/HR + breast subtype based on the real-world SEER database analysis. Although management of de novo stage IV BC remains a challenging task for breast surgeons, PMRT significantly prolonged median CSS (PMRT group 54 months vs. non-RT group 43 months) and OS (PMRT group 49 months vs. non-RT group 39 months).

Radiation oncologists may treat de novo metastatic BC patients with PMRT for various reasons. Whether these patients need PMRT and how to select the beneficial subgroup are urgent clinical problems that need to be solved. For patients with de-novo stage IV BC who underwent a modified radical mastectomy, studies on the role of PMRT in the group are rare. A recent study concluded that surgery + radiation therapy had the highest OS in patients with metastatic BC. However, this study did not explore the role of PMRT directly [9]. Our research is the first conclusive evidence minimizing group differences by using PSM. We found that PMRT provided meaningful survival benefits in the T3-4 or $\mathrm{N}+$ subgroup and Her2-/HR + breast subtype, especially in the bone metastasis but without the brain metastasis group. This 
result indicated that the T/N stage, BC subtype, and metastatic site at diagnosis could be worked as indicators for performing PMRT in metastatic BC.

Retrospective reports found that RT was used alone or combined with surgery as a locoregional treatment in de novo stage IV BC. The rationale of local treatment included better disease control by restoring immunocompetence, removing the primary tumor bulk, decreasing breast cancer stem cells, reducing the probability of resistance, and reducing growth factors promoting distant metastasis [10-12]. However, a study in an animal model indicated that primary tumor removal might increase metastasis by affecting a host's immunity to the tumor [13].

PMRT has been widely accepted for $\mathrm{BC}$ with $\geq 4$ positive lymph nodes [14]. Radiotherapy, including the chest wall and regional nodes, significantly reduced local-regional recurrence (LRR) rates for clinical stage III or IV advanced patients who achieved pCR to neoadjuvant chemotherapy and in patients with four or more positive nodes [15]. PMRT provided a clear clinical benefit in clinical stage III BC with PCR after neoadjuvant chemotherapy [5]. The ASCO-ASTRO-SSO panel consistently agreed that PMRT reduces the LRR, any recurrence, and mortality for patients with $\mathrm{T} 1-2 \mathrm{BC}$ with $\leq 3$ positive axillary nodes [16]. However, data on the value of PMRT in the de novo stage IV BC group are rare and inconclusive.

To identify the beneficiaries of PMRT, we compared the survival outcomes of different $\mathrm{T}$ or $\mathrm{N}$ stage. The survival benefit of PMRT was observed in the T3-4 or N + group. However, in the T1-2 and lymph nodenegative, PMRT was related to poor outcomes regardless of CSS or OS. Besides, when conducting subgroup analysis in different metastasis sites, we found that brain metastasis significantly influenced the effect of PMRT. The bone metastasis without brain metastasis group was the beneficiaries.

Data have shown that for populations who underwent a mastectomy and axillary dissection of at least levels I and II, PMRT including the chest wall, the supraclavicular or axillary fossa (or both), and the internal mammary chain declined recurrence, breast cancer mortality, and overall mortality for women with node-positive disease. However, no superiority of PMRT was found in women with node-negative disease [17]. In our study, the survival benefit was similar to the above data in that the dominant population benefiting from PMRT is the node-positive group. At the same time, PMRT even reduced CSS and OS in the T1-2NO cohort. Eugene H. et al. reported PMRT provided significantly improved CSS rate in clinically advanced stage IIIB to stage IV disease who achieved PCR to neoadjuvant chemotherapy, and it should be noted that patients in this study were staged based on the 1988 American Joint Committee on Cancer Staging. Only those with ipsilateral supraclavicular lymph node involvement without other distant metastases were enrolled in the analysis [15].

When performed subgroup analysis based on the BC subtype, PMRT improved survival benefit in HR+/HER2-, the effect of PMRT did not achieve statistical significance in other BC subtypes. Given that the HER2 subtype could be predictive of locoregional recurrence and trastuzumab use could markedly reduce the risk of LRR $[18,19]$, the effect of PMRT on outcome could be affected by the utilization of trastuzumab in HER2(+) patients. Our results were partly unanimous with the previous study of stage II-III $\mathrm{BC}$, showing that survival superiority after PMRT was observed only in those with good prognostic 
predictors, including HR + and HER2-. No benefit in the HR- and HER-2 + patients and no significantly improved OS was seen after PMRT for the triple-negative with fewer reductions in LRR [18]. In another Chinese cohort staged as T1-4, N2-3, and M0, PMRT was significantly associated with reduced recurrence and mortality in luminal $A$ and decreased the recurrence in luminal $B$ patients but not for HER2 enriched or triple-negative groups [20]. In the present study, we find a consistent result in triple-negative BC.

Because of the retrospective nature, this population-based study had several significant limitations. Systemic therapies, including endocrine treatment, targeted therapy, detailed chemotherapy regimens or timing of chemotherapy, and detailed radiotherapy information were not reported. Due to the missing information, further subgroups analysis could not be performed, which may affect the indication for PMRT and the interpretation of the findings. Furthermore, only four common metastasis sites, including the brain, bone, liver, and lung metastasis, were reported in some patients. More detailed information was not available. The lack of relevant data could affect statistical analysis and lead to some beneficiaries missed. The evidence of identifying beneficiaries based on metastasis sites was indicative though not adequate. Besides, the effect of PMRT will be influenced by tumor residue. Unfortunately, this information was not available, which also impacted the study results. Although our findings challenge current standards limiting resection for the palliation with a possibility of overtreatment of PMRT in de novo metastatic BC, strong evidence about the survival benefit of PMRT in patients who underwent mastectomy is not currently available.

\section{Conclusions}

In conclusion, despite the low 5-year survival rate in de novo stage IV BC patients, our study demonstrated that patients treated with PMRT after modified radical mastectomy had a significantly better outcome in selected T3-4 or N + patients based on the real-world analysis. However, these findings need to be validated by further study before being incorporated into clinical practice.

\section{Declarations}

\section{Conflict of Interest}

The authors declare that the research was conducted in the absence of any commercial or financial relationships that could be construed as a potential conflict of interest.

\section{Author information}

Department of Radiation Oncology, Shandong Provincial Qianfoshan Hospital, Shandong University, Jinan, Shandong Province, China

Ning Liang, and Xinyi Huang. 
Department of Oncology, The First Affiliated Hospital of Shandong First Medical University \& Shandong Provincial Qianfoshan Hospital, Jinan, Shandong Province, China

Ning Liang, Tiantian Tian , and Pingping Hu.

Shandong Lung Cancer Institute, Jinan, Shandong Province, China

Ning Liang, Tiantian Tian , and Pingping Hu.

\section{Funding}

This research was funded by the National Natural Science Foundation of China (grant no. 81672974, no. 81803043, and no. 81602719).

\section{Acknowledgments}

We gratefully acknowledge the Surveillance, Epidemiology, and End Results (SEER) program tumor registries for the creation of the SEER-Medicare database.

\section{References}

1. Sant M, Allemani C, Berrino F, Coleman MP, Aareleid T, Chaplain G et al (2004) Breast carcinoma survival in Europe and the United States. Cancer 100(4):715-722 r.20038. PubMed PMID: 14770426.. ) ). doi: 10.1002/cnc

2. Singletary SE, Walsh G, Vauthey JN, Curley S, Sawaya R, Weber KL et al (2003) A role for curative surgery in the treatment of selected patients with metastatic breast cancer. Oncologist 8(3):241-251. doi:10.1634/theoncologist.8-3-241. PubMed PMID: 12773746

3. Barbie TU, Golshan M (2018) De Novo Stage 4 Metastatic Breast Cancer: A Surgical Disease? Ann Surg Oncol 25(11):3109-3111. doi:10.1245/s10434-018-6664-6. PubMed PMID: 30019303

4. Tosello G, Torloni MR, Mota BS, Neeman T, Riera R. Breast surgery for metastatic breast cancer. The Cochrane database of systematic reviews (2018) 3:CD011276. doi:

10.1002/14651858.CD011276.pub2. PubMed PMID: 29542106; PubMed Central PMCID: PMC6494198

5. McGuire SE, Gonzalez-Angulo AM, Huang EH, Tucker SL, Kau SW, Yu TK et al (2007)

Postmastectomy radiation improves the outcome of patients with locally advanced breast cancer who achieve a pathologic complete response to neoadjuvant chemotherapy. Int J Radiat Oncol Biol Phys 68(4):1004-1009 doi: 10.1016/j.jjrobp.2007.01.023. PubMed PMID: 17418973; PubMed Central PMCID: PMC4329732

6. Andre F, Slimane K, Bachelot T, Dunant A, Namer M, Barrelier A et al (2004) Breast cancer with synchronous metastases: trends in survival during a 14-year period. Journal of clinical oncology: official journal of the American Society of Clinical Oncology 22(16):3302-3308 doi:

10.1200/JCO.2004.08.095. PubMed PMID: 15310773 
7. Gnerlich J, Jeffe DB, Deshpande AD, Beers C, Zander C, Margenthaler JA (2007) Surgical removal of the primary tumor increases overall survival in patients with metastatic breast cancer: analysis of the 1988-2003 SEER data. Ann Surg Oncol 14(8):2187-2194. doi:10.1245/s10434-007-9438-0. PubMed PMID: 17522944

8. Choi SH, Kim JW, Choi J, Sohn J, Kim SI, Park S et al (2018) Locoregional Treatment of the Primary Tumor in Patients With De Novo Stage IV Breast Cancer: A Radiation Oncologist's Perspective. Clin Breast Cancer 18(2):e167-e178 doi: 10.1016/j.clbc.2017.06.002. PubMed PMID: 28689012

9. Kim KN, Qureshi MM, Huang D, Ko NY, Cassidy M, Oshry L et al (2020) The Impact of Locoregional Treatment on Survival in Patients With Metastatic Breast Cancer: A National Cancer Database Analysis. Clin Breast Cancer. doi:10.1016/j.clbc.2019.12.010. PubMed PMID: 32089454

10. Bourgier C, Khodari W, Vataire AL, Pessoa EL, Dunant A, Delaloge S et al (2010) Breast radiotherapy as part of locoregional treatments in stage IV breast cancer patients with oligometastatic disease. Radiotherapy oncology: journal of the European Society for Therapeutic Radiology Oncology 96(2):199-203 2.028. PubMed PMID: 20347167.. ) ). doi: 10.1016/j.radonc.2010.0

11. Danna EA, Sinha P, Gilbert M, Clements VK, Pulaski BA, Ostrand-Rosenberg S (2004) Surgical removal of primary tumor reverses tumor-induced immunosuppression despite the presence of metastatic disease. Cancer research 64(6):2205-2211. PubMed PMID: 15026364

12. Karnoub AE, Dash AB, Vo AP, Sullivan A, Brooks MW, Bell GW et al (2007) Mesenchymal stem cells within tumour stroma promote breast cancer metastasis. Nature 449(7162):557-563. doi:10.1038/nature06188. PubMed PMID: 17914389

13. Fisher B, Gunduz N, Coyle J, Rudock C, Saffer E (1989) Presence of a growth-stimulating factor in serum following primary tumor removal in mice. Cancer research 49(8):1996-2001. PubMed PMID: 2702641

14. Tseng YD, Uno H, Hughes ME, Niland JC, Wong YN, Theriault R et al (2015) Biological Subtype Predicts Risk of Locoregional Recurrence After Mastectomy and Impact of Postmastectomy Radiation in a Large National Database. Int J Radiat Oncol Biol Phys 93(3):622-630 7.006. PubMed PMID: 26461004.. ) ). doi: 10.1016/j.ijrobp.2015.0

15. Huang EH, Tucker SL, Strom EA, McNeese MD, Kuerer HM, Buzdar AU et al (2004) Postmastectomy radiation improves local-regional control and survival for selected patients with locally advanced breast cancer treated with neoadjuvant chemotherapy and mastectomy. Journal of clinical oncology: official journal of the American Society of Clinical Oncology 22(23):4691-4699 doi: 10.1200/JCO.2004.11.129. PubMed PMID: 15570071

16. Recht A, Comen EA, Fine RE, Fleming GF, Hardenbergh PH, Ho AY et al Postmastectomy Radiotherapy: An American Society of Clinical Oncology, American Society for Radiation Oncology, and Society of Surgical Oncology Focused Guideline Update. Practical radiation oncology (2016) 6(6):e219-e34. doi: 10.1016/j.prro.2016.08.009. PubMed PMID: 27659727

17. Ebctcg McGaleP, Taylor C, Correa C, Cutter D, Duane F et al (2014) Effect of radiotherapy after mastectomy and axillary surgery on 10-year recurrence and 20-year breast cancer mortality: meta- 
analysis of individual patient data for 8135 women in 22 randomised trials. Lancet 383(9935):2127-2135. doi:10.1016/S0140-6736(14)60488-8. PubMed PMID: 24656685; PubMed Central PMCID: PMC5015598

18. Kyndi M, Sorensen FB, Knudsen H, Overgaard M, Nielsen HM, Overgaard J et al (2008) Estrogen receptor, progesterone receptor, HER-2, and response to postmastectomy radiotherapy in high-risk breast cancer: the Danish Breast Cancer Cooperative Group. Journal of clinical oncology: official journal of the American Society of Clinical Oncology 26(9):1419-1426.

doi:10.1200/JC0.2007.14.5565. PubMed PMID: 18285604

19. Kiess AP, McArthur HL, Mahoney K, Patil S, Morris PG, Ho A et al (2012) Adjuvant trastuzumab reduces locoregional recurrence in women who receive breast-conservation therapy for lymph nodenegative, human epidermal growth factor receptor 2-positive breast cancer. Cancer 118(8):19821988. doi:10.1002/cncr.26484. PubMed PMID: 21887681

20. Wu SG, He ZY, Li Q, Li FY, Lin Q, Lin HX et al (2012) Predictive value of breast cancer molecular subtypes in Chinese patients with four or more positive nodes after postmastectomy radiotherapy. Breast 21(5):657-661 doi: 10.1016/j.breast.2012.07.004. PubMed PMID: 22835918

\section{Figures}




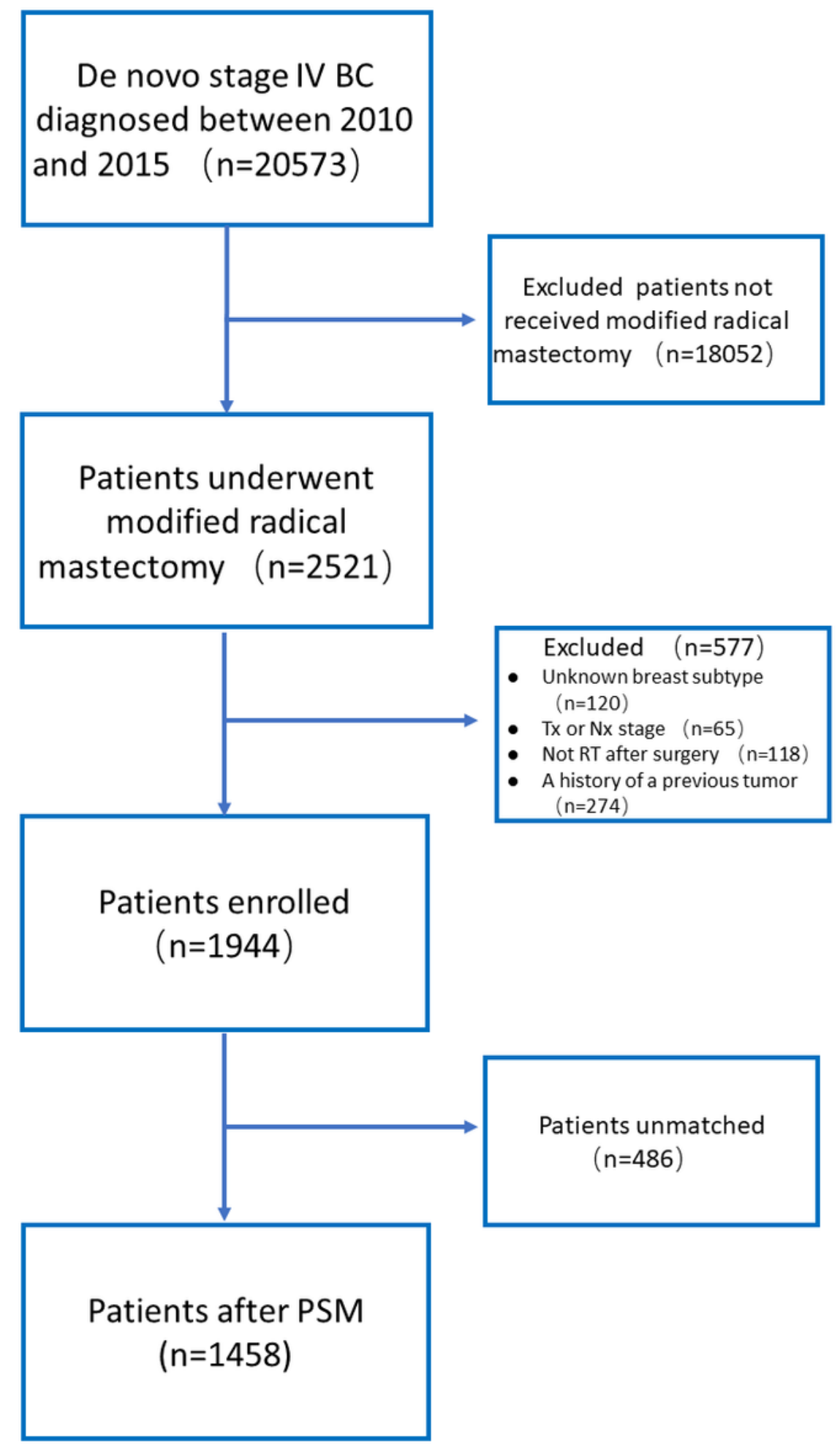

\section{Figure 1}

The flow chart for patients' enrollment. 
A

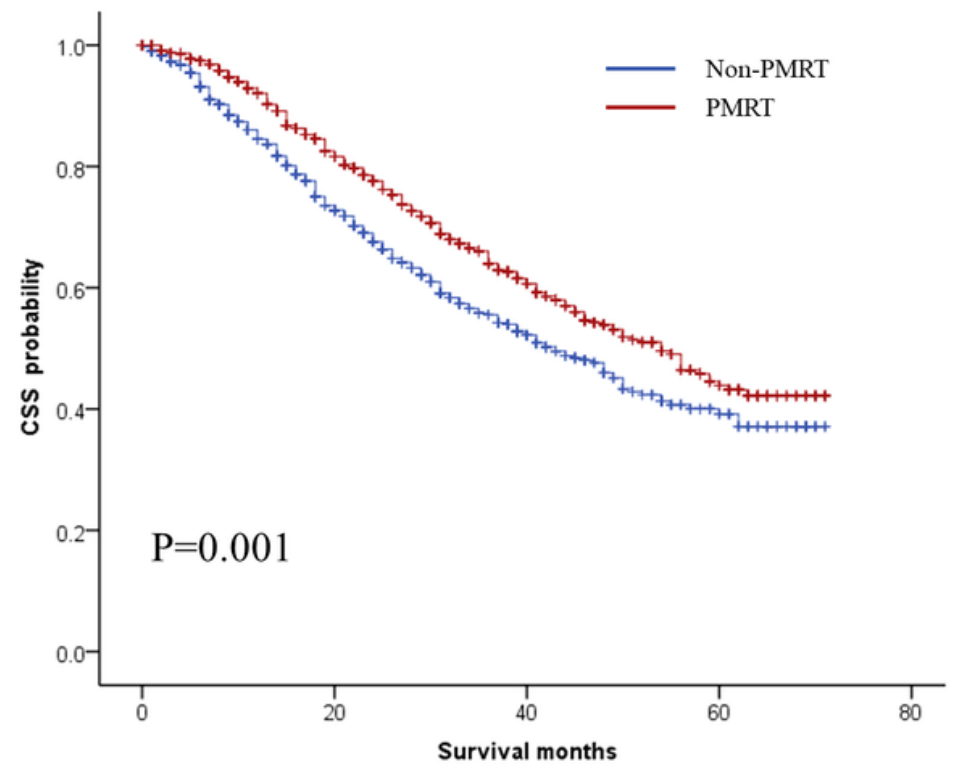

B

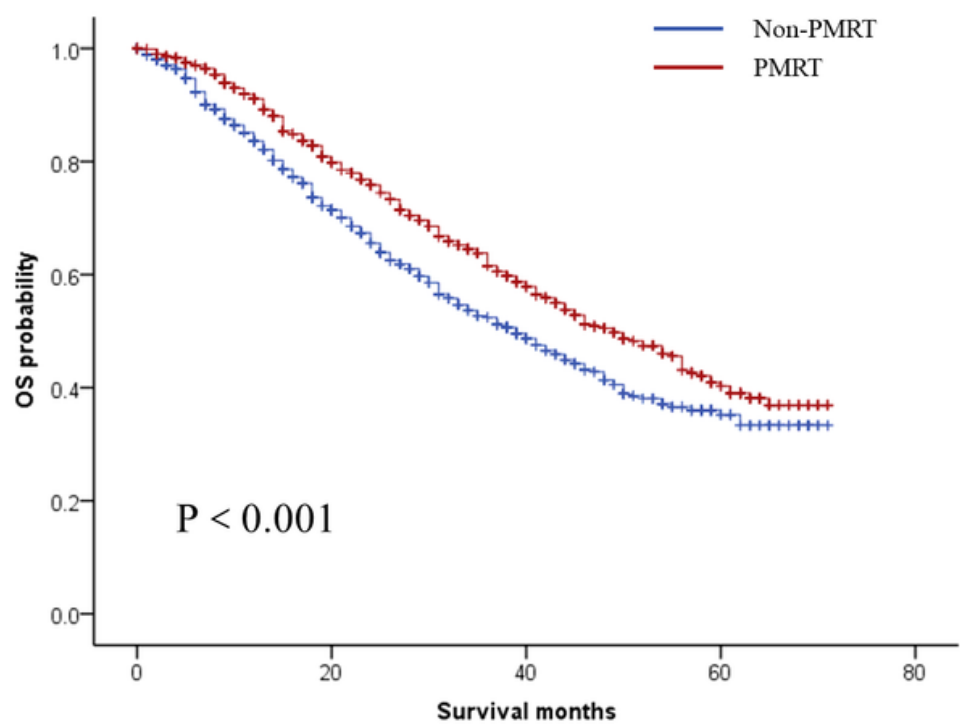

\section{Figure 2}

Kaplan-Meier survival curves showing survival in patients underwent PMRT. A, CSS for PMRT and nonPMRT group. B, OS for PMRT and non-PMRT group. Blue line: Non-PMRT group; Red line: PMRT group. PMRT, post mastectomy radiotherapy; CSS, cancer specific survival; OS, overall survival. 
A

C
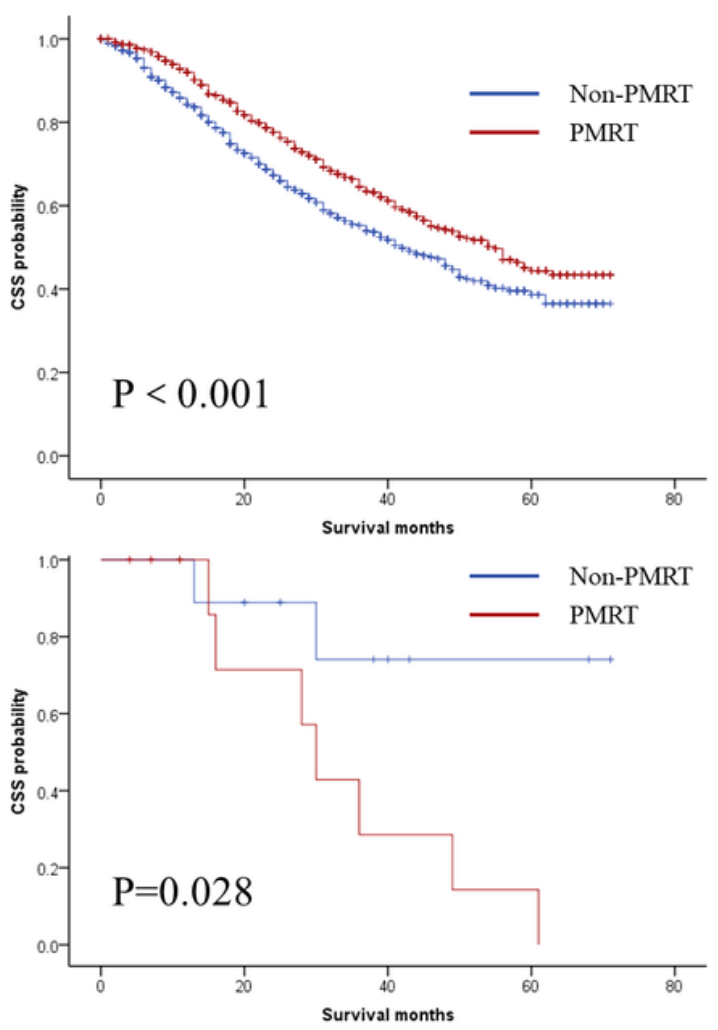

B

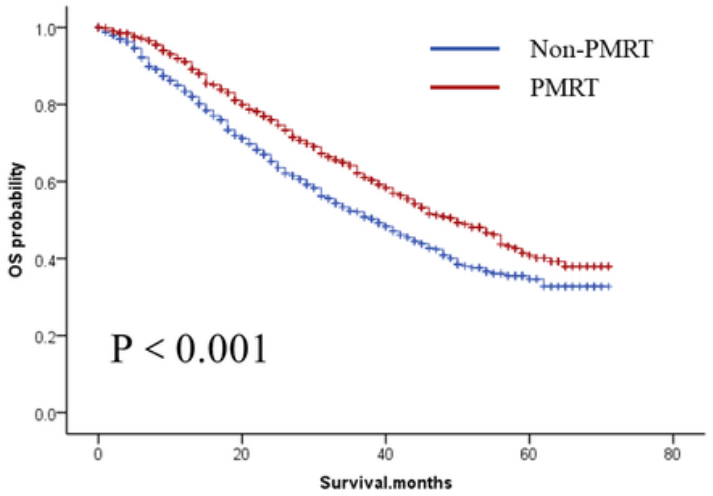

D

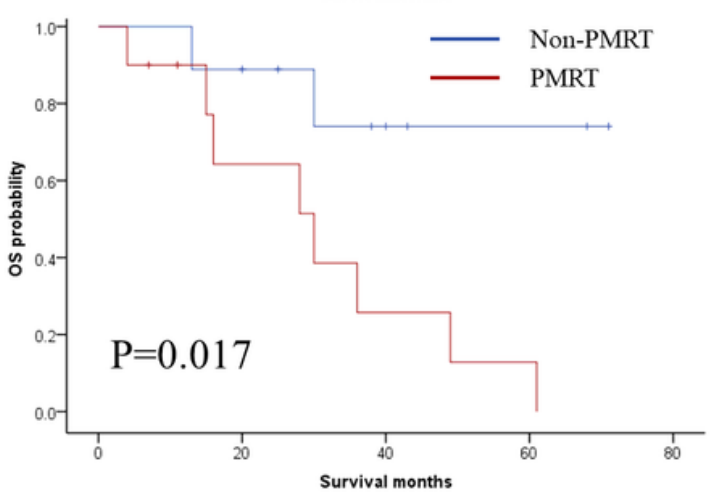

\section{Figure 3}

Subgroups analyses based on T/N stage. A, Survival curves for CSS in T3-4 or N+ group. B, Survival curves for OS in T3-4 or N+ group. C, Survival curves for CSS in T1-2 and N-group. D, Survival curves for OS in T1-2 and N- group. Blue line: Non-PMRT group; Red line: PMRT group. PMRT, post mastectomy radiotherapy; CSS, cancer specific survival; OS, overall survival. 
A

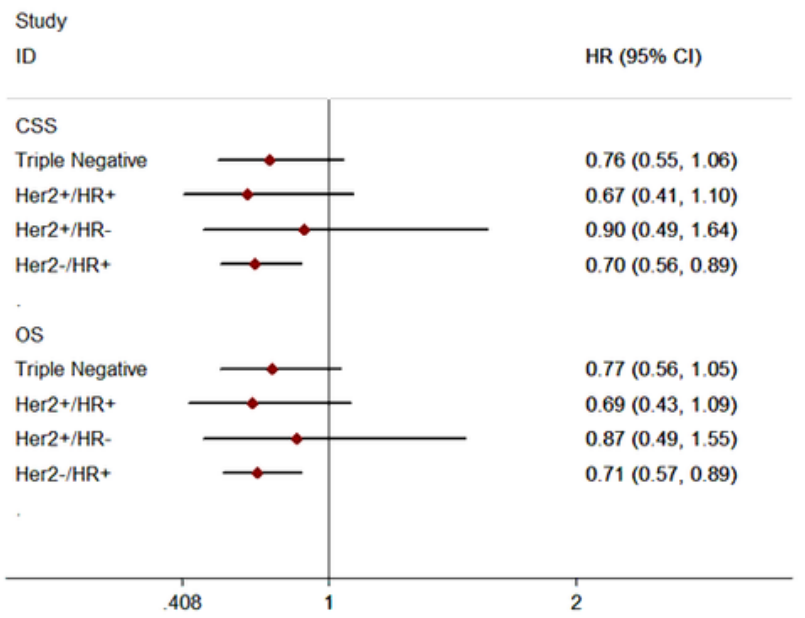

B

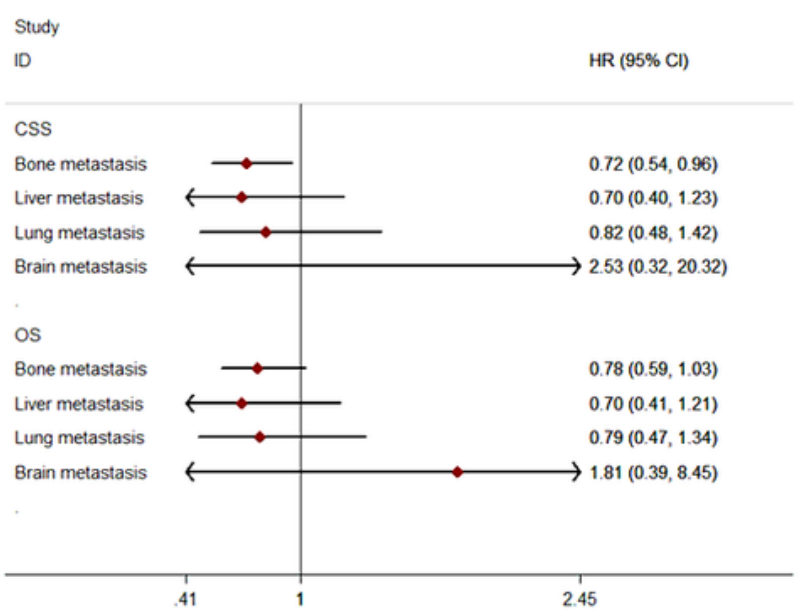

$\mathbf{C}$

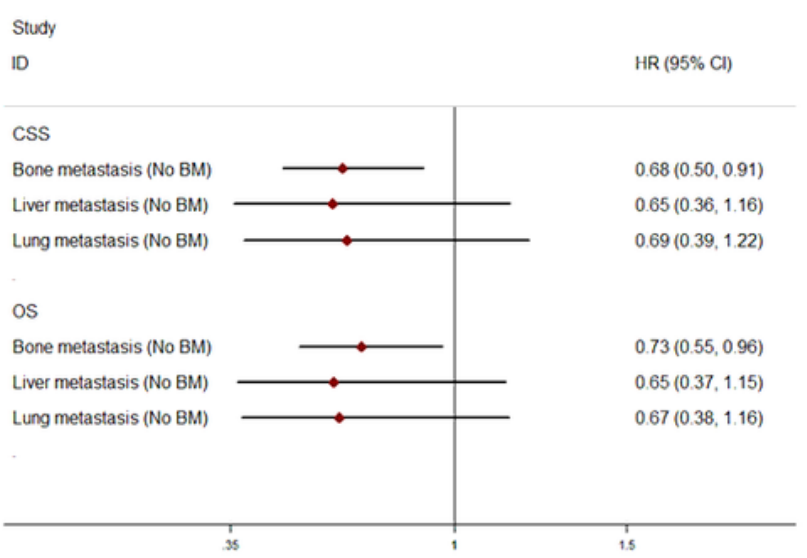

Figure 4

Forest plot to assess the effect of PMRT based on metastasis site and breast cancer subtype. A, Forest plot of PMRT in different breast subtypes. B, Forest plot of PMRT in various metastasis sites. C, Forest plot of PMRT in various metastasis sites in the non-brain metastases cohort. PMRT, post mastectomy radiotherapy; CSS, cancer specific survival; OS, overall survival. BM, brain metastasis. 